OPEN ACCESS

Edited by:

Bing Xia,

Nanjing Forestry University, China

Reviewed by:

Parikshit Moitra

University of Maryland, Baltimore, United States

Xuemei Ge,

Nanjing Forestry University, China

*Correspondence:

Zhongyu Duan

zyduan@hebut.edu.cn

Yu Yi

yiyu@nanoctr.cn

Hao Wang

wanghao@nanoctr.cn

${ }^{+}$These authors have contributed equally to this work

Specialty section:

This article was submitted to

Nanobiotechnology,

a section of the journal

Frontiers in Bioengineering and

Biotechnology

Received: 24 September 2021

Accepted: 01 November 2021

Published: 26 November 2021

Citation:

Luo Z, Gao Y, Duan Z, YY Y and Wang H (2021) Mitochondria-Targeted SelfAssembly of PeptideBased Nanomaterials.

Front. Bioeng. Biotechnol. 9:782234. doi: 10.3389/fbioe.2021.782234

\section{Mitochondria-Targeted Self-Assembly of Peptide-Based Nanomaterials}

\author{
Zhen Luo ${ }^{1,2 \dagger}$, Yujuan $\mathrm{Gao}^{2 \dagger}$, Zhongyu Duan ${ }^{1 *}, \mathrm{Yu}^{\mathrm{Yi}^{2,3 *}}$ and Hao Wang $^{2,3 *}$ \\ ${ }^{1}$ School of Chemical Engineering and Technology, Hebei University of Technology, Tianjin, China, ${ }^{2}$ CAS Center for Excellence in \\ Nanoscience, CAS Key Laboratory for Biomedical Effects of Nanomaterials and Nanosafety, National Center for Nanoscience and \\ Technology (NCNST), Beijing, China, ${ }^{3}$ Center of Materials Science and Optoelectronics Engineering, University of Chinese \\ Academy of Sciences, Beijing, China
}

Mitochondria are well known to serve as the powerhouse for cells and also the initiator for some vital signaling pathways. A variety of diseases are discovered to be associated with the abnormalities of mitochondria, including cancers. Thus, targeting mitochondria and their metabolisms are recognized to be promising for cancer therapy. In recent years, great efforts have been devoted to developing mitochondria-targeted pharmaceuticals, including small molecular drugs, peptides, proteins, and genes, with several molecular drugs and peptides enrolled in clinical trials. Along with the advances of nanotechnology, self-assembled peptide-nanomaterials that integrate the biomarker-targeting, stimuliresponse, self-assembly, and therapeutic effect, have been attracted increasing interest in the fields of biotechnology and nanomedicine. Particularly, in situ mitochondria-targeted self-assembling peptides that can assemble on the surface or inside mitochondria have opened another dimension for the mitochondria-targeted cancer therapy. Here, we highlight the recent progress of mitochondria-targeted peptidenanomaterials, especially those in situ self-assembly systems in mitochondria, and their applications in cancer treatments.

Keywords: mitochondrion, self-assembly, peptide, enzyme, nanomaterials, cancer therapy

\section{INTRODUCTION}

Mitochondria, the dynamic sub-organelles in mammalian cells, are well known to be involved in the generation of adenosine triphosphate (ATP) (Roger et al., 2017). They are composed of mitochondrial membranes that include a porous outer membrane and an inner membrane with a space, and a mitochondrial matrix inside (Frey and Mannella, 2000). With their own genome and fission signatures (Gray et al., 1999; Jiao et al., 2021; Kleele et al., 2021), mitochondria also participate in other essential physiological functions in the body, such as macromolecule biosynthesis (Spinelli and Haigis, 2018) and cell proliferation (Diebold et al., 2019), differentiation (Seo et al., 2018), apoptosis (Bock and Tait, 2020), information transmission (Chandel, 2015), etc. Dysfunctions of mitochondria are discovered to be associated with a series of diseases that threaten human health (Nunnari and Suomalainen, 2012), including neurodegeneration (Devine and Kittler, 2018), cardiovascular disease (Siasos et al., 2018), and cancer (Ward and Thompson, 2012). Increasing evidence has revealed the relevance between the energetic production, metabolic biosynthesis, and singling pathways of mitochondria with the carcinogenesis (Weinberg and Chandel, 2015). Therefore, the mitochondrion has been recognized as a promising target to improve cancer therapeutics (Fulda et al., 2010; Vasan et al., 2020; Gao et al., 2021).

Currently, mitochondria can be intervened by either using the mitochondria-targeted reagents or modulating the specific targets, gene transcriptions, and kinase activities within or outside 
mitochondria (Smith et al., 2012). Particularly, with the discovery of several types of targeted compounds, the mitochondriatargeted approach attracts increasing attentions (Zinovkin and Zamyatnin, 2019). For instance, lipophilic cations, such as triphenylphosphonium (TPP) and dequalinium, are first discovered to target mitochondria (Murphy and Smith, 2007). TPP contains a positively charged phosphorus atom delocalized over three hydrophobic benzene rings (Liberman et al., 1969). The unique structure allows TPP to target the mitochondrial membrane due to the negative membrane potential and the favored activation energy when crossing phospholipid bilayers, resulting in a thousand-fold enhancement in the mitochondrial accumulation (Murphy and Hartley, 2018). Till now, two TPPbased small molecular antioxidants, MitoQ and SkQ1 (Kelso et al., 2001; Skulachev, 2007), have been enrolled in clinical trials for treatments of Parkinson disease, chronic kidney disease, and hepatitis $\mathrm{C}$, as well as the dry-eye syndrome, respectively (Battogtokh et al., 2018; Kang, 2018; Jeena MT. et al., 2020). The second category is the mitochondria-targeted peptides, mainly including Szeto-Schiller (SS) peptides and mitochondria-penetrating peptides (MMPs) (Horton et al., 2008; Li and Huang, 2020). These peptides usually consist of hydrophobic and positively charged amino acids, which are assumed to target mitochondria driven by the negative membrane potential and the interaction with phospholipids on mitochondrial inner membranes (Zhao et al., 2004; Birk et al., 2013; Jean et al., 2016). One formulation of SS peptide (MTP-131) has been enrolled in clinical trials for treatments of heart attack and skeletal muscle mitochondrial dysfunction in the elderly. Besides, the mitochondrial precursor protein is a natural mitochondria-targeted species, which enters mitochondria via the mitochondrial protein import machinery (Neupert and Herrmann, 2007). These proteins contain a cleavable $\mathrm{N}$-terminal targeted sequence, which is cleaved by mitochondrial peptidases once entering mitochondria (Wasilewski et al., 2017). In recent years, self-assembled peptide-nanomaterials are emerging as a new type of mitochondria-targeted category, due to their designable feature to combine the targeting, biological responsive, self-assembling, and therapeutic properties (Qi et al., 2018).

In this review, we focus on the mitochondria-targeted selfassembled peptide-nanomaterials developed in recent years. The latest strategies and advances for constructing self-assembling peptides that target and assemble in mitochondria are highlighted, including the equipment of mitochondria-targeted ligands, the introduction of a stimuli-responsive mechanism to trigger the self-assembly in situ, and so on. Meanwhile, we briefly discuss the application of these nanomaterials in cancer therapy.

\section{SELF-ASSEMBLING PEPTIDE}

Peptides are usually defined as the biomacromolecules that contain less than 50 amino acids linked by peptide bonds, with the intrinsic characteristics of folding and bioactivities like recognition and response. Since the emergences of technologies for the peptide manufacture and screening, especially the solid-phase peptide synthesis proposed by Merrifield in 1963 (Merrifield, 1963) and the phage display described by Smith in 1985 (Smith, 1985), numerous peptide-based pharmaceuticals and functional materials have been developed (Figure 1A) (Hosoyama et al., 2019; Li et al., 2020; Lopez-Silva and Schneider, 2021; Muttenthaler et al., 2021). Particularly, self-assembling peptides have attracted increasing interest due to their improved stability and biological performance (Guyon et al., 2018; Levin et al., 2020), and have been applied in a wide range of fields including the tissue engineering (Gelain et al., 2020; Zhang et al., 2021), drug delivery (Moitra et al., 2014; Abbas et al., 2017; Yang J. et al., 2020; Kumar et al., 2020; Ji et al., 2021), catalysis (Rufo et al., 2014; Wang M. et al., 2020; Liu Q. et al., 2021; Chen et al., 2021), semi-conducting device (Tao et al., 2017), and energy materials (Hu et al., 2018; Lee et al., 2018; Nguyen et al., 2021). With the molecular basis to form secondary structures including the $\alpha$-helix and $\beta$-sheet, the self-assembling peptides can assemble into well-defined nanostructures like nanofibrils driven by non-covalent interactions, such as the hydrophobic interaction, electrostatic interaction, $\pi-\pi$ stacking, hydrogen bond, etc (Hendricks et al., 2017; Hu et al., 2020; Zheng et al., 2021). For instance, the diphenylalanine peptide (FF), the most widely investigated selfassembling peptide, can assemble into either the nanofiber, nanotube, nanosphere, or nanoarray on the surface, by using properly mixed solvents and kinetic controls, or vapor deposition (Reches and Gazit, 2003; Wei et al., 2017; Zhao et al., 2019). The rapid development of self-assembling peptides can be traced back to 1990s (Zhang, 2020). The peptides in early researches are limited and mainly inspired from natural proteins especially amyloid proteins (Zhang, 2003), like FF and KLVFF. The developments of machine learning (Jumper et al., 2021) and one-bead one-compound (OBOC) combinatorial library (Lam et al., 1991) technologies make the screening of self-assembling peptides in a large-scale manner possible. For instance, Frederix et al. developed a computational simulation tool based on the aggregation propensity and amphiphilicity of peptides, to rapidly screen the self-assembling tripeptides in all 8,000 possible sequences and guided the discoveries of several unreported tripeptides that could form hydrogels (Frederix et al., 2015). In another work, Li et al. focused on the relationship between the chemical structures of peptides and their albitites to form hydrogels, applying machine learning to generate a hydrogel library with more than 2,000 self-assembling dipeptides (Li F. et al., 2019). Besides computational simulations (Moitra et al., 2017), Yang et al. recently capped a hydrophobicitysensitive probe, the nitro-1,2,3-benzoxadiazole (NBD), to the $\mathrm{N}$-terminus of peptides on beads in the OBOC library, achieving the rapid screening of self-assembling pentapeptides experimentally (Yang et al., 2021).

\section{SELF-ASSEMBLED PEPTIDE-NANOMATERIALS FOR TARGETING MITOCHONDRIA}

In recent years, targeted drug delivery systems have shown promising potentials in precision and personalized medicine, with reduced side effects (Yi et al., 2019; Mi et al., 2020; Manzari et al., 2021). In this regard, the integration with the 


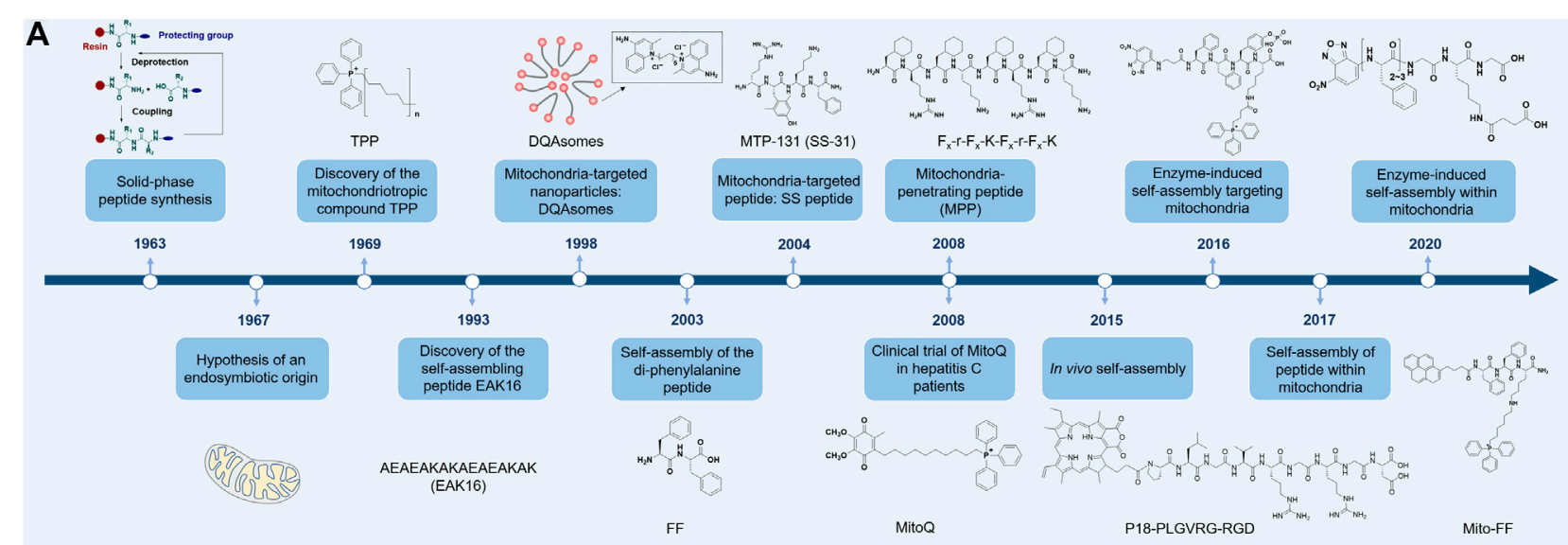

B

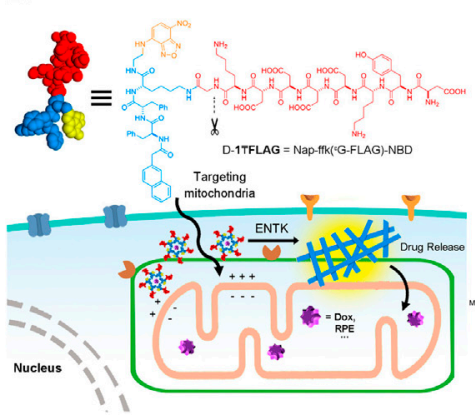

C

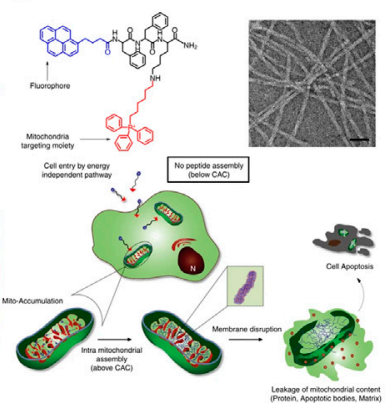

D

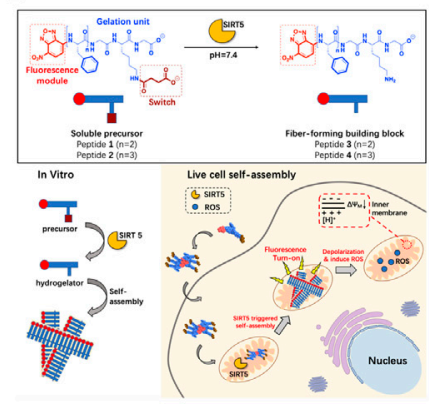

E

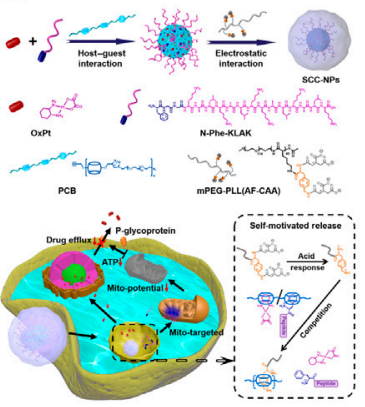

FIGURE 1 | (A) A brief timeline of selected events for mitochondria-targeted self-assembly of peptide-nanomaterials. The references are shown in Supplementary Table S1. (B) In situ enzyme-instructed self-assembly of branched peptides around mitochondria. Reproduced with permission from ref (He et al., 2018). Copyright 2018 American Chemical Society. (C) In situ self-assembly of peptide amphiphiles in mitochondria due to the enhanced accumulation by targeting. Reproduced with permission under a Creative Commons CC BY License from ref (Jeena et al., 2017). Copyright 2017 Springer Nature. (D) In situ enzyme-instructed self-assembly of peptides in mitochondria. Reproduced with permission from ref (Yang L. et al., 2020). Copyright 2020 American Chemical Society. (E) Self-motivated release of the mitochondria-cytotoxic peptide to strengthen the chemotherapy toward drug-resistant cancer cells. This figure has been published in CCS Chemistry 2021; SelfMotivated Supramolecular Combination Chemotherapy for Overcoming Drug Resistance Based on Acid-Activated Competition of Host-Guest Interactions is available online at 10.31635/ccschem.021.202100964; https://www.chinesechemsoc.org/doi/10.31635/ccschem.021.202100964.

biomarker-targeting, enzyme-response, and treatment makes the self-assembling peptides as candidates for functional nanomaterials and smart nanomedicines more than scaffolds in hydrogels. This endeavor has been promoted by the establishment of several important concepts including the peptide amphiphiles (Lowik and van Hest, 2004; Cui et al., 2010), the enzyme-instructed self-assembly (EISA) (Zhou and $\mathrm{Xu}, 2015$; He et al., 2020c), and the in vivo self-assembly (Zhang et al., 2015; He P.-P. et al., 2020; Mamuti et al., 2021). Since mitochondria serve as a potential target for cancers (Guo et al., 2021; Liew et al., 2021), dozens of mitochondria-targeted selfassembled peptide-nanomaterials have been reported (Table 1), including the pre-assembled peptide-nanomaterials that locate mitochondria and in situ self-assembling peptides that assemble in mitochondria. In this section, we discuss the former.

A typical approach to construct the mitochondria-targeted self-assembling peptide is to equip a targeting motif to a selfassembling peptide. For instance, Standley et al. combined the $a$-helical (KLAKLAK) 2 (KLAK) peptide, a cytotoxic peptide that breaks mitochondrial membranes (Ellerby et al., 1999), with a hydrophobic alkyl tail and a $\beta$-sheet forming peptide to afford a mitochondria-targeted peptide amphiphile (Standley et al., 2010). This peptide amphiphile could assemble into nanofibers, which were demonstrated to enter the breast cancer cells, then locate and disrupt the mitochondrial membranes. To increase the targeting efficacy, stimuli such as the endogenous enzyme, redox, and acidic environments, as well as the exogenous light and ultrasound, are employed to guide the targeted selfassemblies (Chen et al., 2018b; Jiang et al., 2021). For instance, Wang et al. reported an alkaline phosphatase (ALP)-instructed self-assembling peptide for targeting mitochondria (Wang et al., 2016). The peptide consisted of a mitochondria-targeting motif (TPP), a self-assembling backbone (FFYK), an enzymeresponsive phosphorylated tyrosine, and a fluorophore (NBD). Upon dephosphorylation by ALP overexpressed on cancer cell membranes, the peptide became more hydrophobic and selfassembled into nanofibers. After endocytosis and endosomal escape, the peptide-assemblies accumulated to mitochondria assisted by TPP, resulting in mitochondrial dysfunction and cell death. Notably, under the experimental concentration, the peptide did not form assemblies in the low ALP-expressed HS-5 (normal human bone marrow stromal) cells. 
TABLE 1 | Recent progress of mitochondrial-targeted self-assembly of peptide-nanomaterials.

Materials

Peptide components ${ }^{\mathrm{a}}$

Targeting mechanism

\section{Assembling}

modules

Applications

References

Peptide amphiphile Pyrene-FFK(TPP)

Peptide amphiphile Pyrene-FFK(TPP) and pyrene-ffk (TPP)

Peptide amphiphile $\quad \mathrm{C}_{16}$-MIASHLLAYFFTELN-KVLKQRAKKK

Peptide amphiphile DYKDDDDKGE $\left(\mathrm{C}_{16}\right)_{2}$

Peptide amphiphile Cy5-KLVFF-TPP

Peptide amphiphile Pyrene-FFK(TPP)

Peptide amphiphile Cy3-TPP/FF and Cy5-TPP/FF

$\begin{array}{ll}\text { Self-assembling } & \text { NBD-FF } \text { PK } \\ \text { peptide } & \\ \begin{array}{l}\text { Self-assembling } \\ \text { branched peptide }\end{array} & \text { Nap-ffk (GDYKDDDDK)-NBD }\end{array}$

Self-assembling NBD-FFFGK (succ)G and Fmoc-FFFGK (succ)G

peptide

\author{
Self-assembling Nap-ffk (GDYKDDDDK)y \\ peptide \\ Self-assembling PEG-thioketal-K(P18)-(KLAKLAK $)_{2}$ \\ peptide
}

Peptide/pDNA self- MLSLRQSIRFFK-(KH) $)_{9}$ and

assembly

MLFNLRILLNNAAFRNGHNFMVRNFRCGQPLQ-(KH)
TPP ligand for targeting mitochondrial membrane

TPP ligand for targeting mitochondrial membrane

FF

TPP ligand for targeting mitochondrial membrane

TPP ligand for targeting mitochondrial membrane

Targeting mitochondrial VDAC1 by the peptide (MIASHLLAYFFTELN) derived from hexokinase-II protein

Enterokinase-induced cleavage of peptide for drug release located at mitochondria

TPP ligand for targeting mitochondrial membrane

KLVFF

TPP ligand for targeting mitochondrial membrane

Enterokinase-induced cleavage of peptide for selfassembly located at mitochondria

Mitochondria-localized SIRT5 enzyme-induced desuccinylation of peptide for intra-mitochondrial selfassembly

Enterokinase-induced cleavage of peptide for selfassembly located at mitochondria

ROS-triggered detachment of PEG to expose KLAK peptides for disrupting mitochondria

Peptides derived from yeast Cytcox (MLSLRQSIRFFK) and human hepatic enzyme ornithine transcarbamylase (MLFNLRILLNNAAFRNGHNFMVRNFRCGQPLQ) for targeting mitochondria

\begin{tabular}{|c|c|c|}
\hline Pyrene-FF & $\begin{array}{l}\text { Intra-mitochondrial } \\
\text { assembly for cancer therapy } \\
\text { in vitro }\end{array}$ & Jeena et al. (2017) \\
\hline $\begin{array}{l}\text { Pyrene-FF and } \\
\text { pyrene-ff }\end{array}$ & $\begin{array}{l}\text { Treatment of colorectal } \\
\text { tumor (HT-29) in vivo }\end{array}$ & $\begin{array}{l}\text { (Jeena et al., 2019; } \\
\text { Jeena et al., 2020b) }\end{array}$ \\
\hline $\mathrm{C}_{16}$ alkyl chain & $\begin{array}{l}\text { Treatment of lung cancer } \\
\text { (A549) cells in vitro }\end{array}$ & Liu et al. (2019) \\
\hline Lipid-like $\mathrm{E}\left(\mathrm{C}_{16}\right)_{2}$ & $\begin{array}{l}\text { Delivery of chloramphenicol } \\
\text { to liver tumoral (HepG2) } \\
\text { mitochondria in vitro }\end{array}$ & He et al. (2020b) \\
\hline KLVFF & $\begin{array}{l}\text { Targeted NIR imaging and } \\
\text { dysfunction of mitochondria } \\
\text { in cervical and lung cancer } \\
\text { (HeLa and A549) cells in vitro }\end{array}$ & $\begin{array}{l}\text { Chandra Saha et al. } \\
\text { (2020) }\end{array}$ \\
\hline Pyrene-FF & $\begin{array}{l}\text { Treatment of sorafenib- } \\
\text { resistant hepatocellular } \\
\text { carcinoma (Huh7) cells } \\
\text { in vitro }\end{array}$ & Hong et al. (2021) \\
\hline FF & $\begin{array}{l}\text { Mitochondria-targeted NIR } \\
\text { imaging and early apoptosis } \\
\text { of cancer cells in vitro }\end{array}$ & Saha et al. (2021) \\
\hline NBD-FF & $\begin{array}{l}\text { Treatment of osteosarcoma } \\
\text { (Saos2) cells in vitro }\end{array}$ & Wang et al. (2016) \\
\hline Nap-ffk(G)-NBD & $\begin{array}{l}\text { Delivery of doxorubicin and } \\
\text { red phycoerythrin to tumoral } \\
\text { (HeLa) mitochondria in vitro }\end{array}$ & He et al. (2018) \\
\hline $\begin{array}{l}\text { NBD-FFF and } \\
\text { Fmoc-FFF }\end{array}$ & $\begin{array}{l}\text { Imaging of SIRT5 in living } \\
\text { cells and improvement of the } \\
\text { anticancer activities of } \\
\text { dichloroacetate, cisplatin, } \\
\text { and paclitaxel toward } \\
\text { cervical cancer (HeLa) cells } \\
\text { in vitro }\end{array}$ & Yang et al. (2020b) \\
\hline Nap-ffky & $\begin{array}{l}\text { Delivery of histone protein } \\
\text { H2B to tumoral (HeLa) } \\
\text { mitochondria in vitro }\end{array}$ & He et al. (2020a) \\
\hline K(P18)-LVFF & $\begin{array}{l}\text { Ultrasound-mediated } \\
\text { treatment of orthotopic } \\
\text { human pancreatic } \\
\text { carcinoma (PANC-1) in vivo, } \\
\text { and photoacoustic imaging- } \\
\text { guided and NIR irradiation- } \\
\text { mediated treatment of } \\
\text { cervical tumor (HeLa) in vivo }\end{array}$ & $\begin{array}{l}\text { (Cheng et al., 2020; } \\
\text { Zhang et al., 2020) }\end{array}$ \\
\hline $\begin{array}{l}\text { Complexation of } \\
(\mathrm{KH})_{9} \text { with pDNA via } \\
\text { electrostatic } \\
\text { interaction }\end{array}$ & $\begin{array}{l}\text { Delivery of pDNA to cellular } \\
\text { mitochondria in vitro }\end{array}$ & Chuah et al. (2016) \\
\hline
\end{tabular}



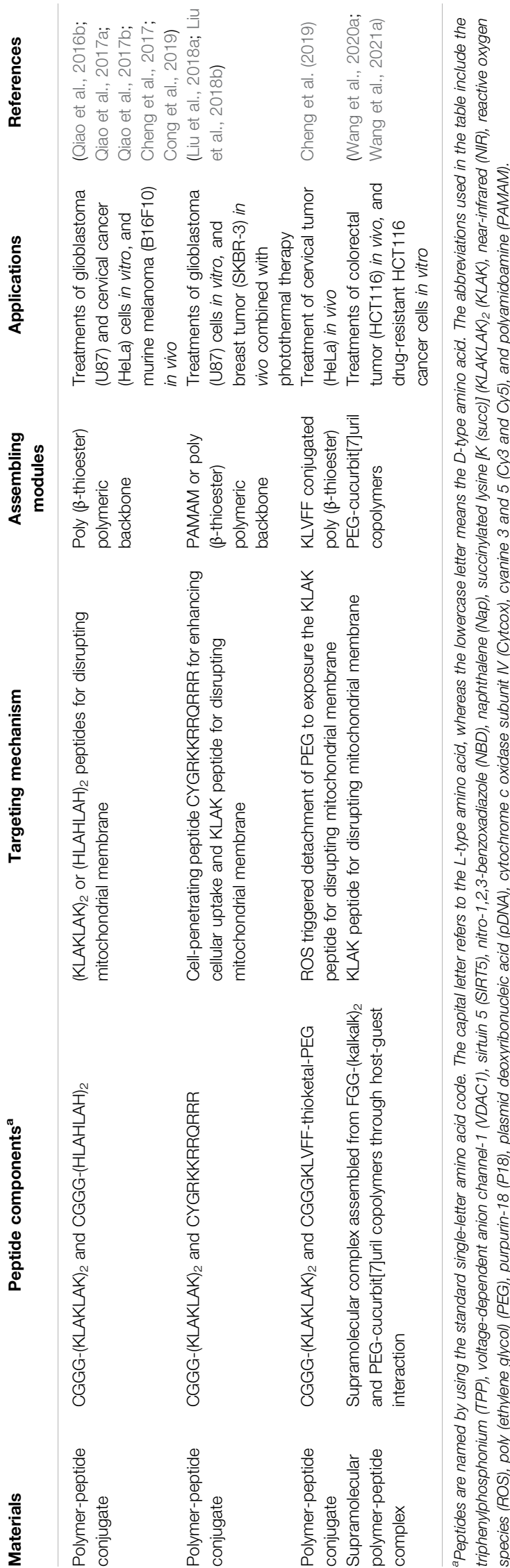

Despite the successes in cultured cells, the self-assembling peptides still face the intrinsic nature of instability in physiological environments, as well as several physiological barriers when applied in the body, such as the rapid clearance in blood, uncontrolled transportation to diseased tissues, insufficient cellular internalization and endosomal escape, etc (Sun et al., 2017). To improve the biological performances in the body, Wang and coworkers reported a series of polymer-peptide conjugates (PPCs) as in vivo self-assembled nanomedicines ( $\mathrm{Li}$ LL. et al., 2019). For instance, Cong et al. reported a type of PPCs that targeted tumoral mitochondria with long blood circulation times (Cong et al., 2019). The PPCs consisted of a poly ( $\beta$-thioester) backbone and KLAK peptides modified with $\mathrm{pH}$ cleavable cis-aconitic anhydride (CAA) moieties and cellpenetrating peptides (TAT: CYGRKKRRQRRR) on the side chains. Upon systemic administration, the hydrophilic PPCs remained soluble as monomers for circulating long in the bloodstream and penetrating deeply into the solid tumors. Once arrived at the tumor tissue, the acidic tumor microenvironment trigged the cleaving of the hydrophilic CAA moieties on PPCs, resulting in the formation of $100 \mathrm{~nm}$ sized nanoparticles decorated with KLAK and TAT peptides. These newly formed nanoparticles entered cancer cells facilitated by TAT peptides, then further located mitochondria and induced apoptosis associated with KLAK peptides.

\section{IN SITU SELF-ASSEMBLY OF PEPTIDE-NANOMATERIALS IN MITOCHONDRIA}

In the previous section, we discussed the assembled peptidenanomaterials that locate mitochondria. Recently, the in situ selfassembly attracts much attention due to its spatiotemporal precision and activable bioeffects, emerging as a frontier in the biomedical field (Deng et al., 2021; Kwek et al., 2021; Liu et al., 2021a; Wang et al., 2021b). The specific enzymes and overexpressed ROS can be used to trigger the self-assembly around or on the surface of mitochondria in situ. As shown in Figure 1B, He et al. reported a mitochondrial enterokinase (ENTK)-instructed branched peptide for self-assembly around mitochondria (He et al., 2018). A hydrophilic ENTK-cleavable Flag-tag (DDDDK) was conjugated to the peptide scaffold, resulting in a micelle-like structure. After cell internalization, the micelles transformed into nanofibers mainly at mitochondria due to the enzymatic cleaving by ENTK. This construction of selfassembling peptides has successfully delivered the chloramphenicol and histone proteins $(\mathrm{H} 2 \mathrm{~B})$ to mitochondria of cancer cells in vitro (He et al., 2020a; He et al., 2020b). Furthermore, to achieve mitochondria-targeting in the body, Cheng et al. constructed a type of ROS-trigged morphologytransformable PPCs driven by the responsive detachment of poly (ethylene glycol) (PEG) chains (Cheng et al., 2019). The PPCs consisted of a poly (vinyl alcohol) backbone with side chainmodifications of PEGylated KLVFF peptides linked by ROScleavable thioketals and KLAK peptides. After administration, the micelle-like PPCs transported in the bloodstream with the 
shield of PEG chains. Once closing to mitochondria, the overgenerated ROS cleaved the thioketal linker to detach PEG chains, resulting in a transformation of micelles to nanofibers that exposed KLAK peptides to disrupt mitochondrial membranes.

To further achieve the precise self-assembly of peptides inside mitochondria, the targeted accumulation-induced assembly and the intramitochondrial protease-instructed assembly have shown promising potentials. Since enough concentration higher than the critical aggregation concentration (CAC) is the basis for molecular assemblies, making the self-assembling peptides with a spatial concentration above $\mathrm{CAC}$ in mitochondria selectively and a concentration below CAC in the cytoplasm is a feasible approach to achieve in situ self-assembly in mitochondria. For instance, Jeena et al. reported a system of in situ self-assembly (Mito-FF) that assembled inside mitochondria through targeted accumulation-induced assembly (Figure 1C) (Jeena et al., 2017). Mito-FF consisted of FFK peptide backbone with a fluorescent pyrene at the $\mathrm{N}$-terminus and TPP at the lysine side chain, with a CAC of $60 \mu \mathrm{M}$. Using a culture medium containing 5 and $10 \mu \mathrm{M}$ Mito-FF, the amphiphilic Mito-FF could efficiently and selectively gather inside mitochondria of cervical cancer (HeLa) cells with a concentration of 3 and $11 \mathrm{mM}$, respectively, thereby aggregating into nanofibers inside mitochondria in situ. Besides the targeted accumulation-induced aggregation, Yang et al. recently utilized the mitochondrial localization enzyme sirtuin 5 (SIRT5) to induce peptide self-assembly inside mitochondria in situ (Figure 1D) (Yang L. et al., 2020). The peptide had a backbone of FFFGKG, with a fluorescent probe NBD at the N-terminus and a succinylated lysine residue. Once entering into mitochondria, the peptide was desuccinylated by SIRT5 to become more hydrophobic, resulting in the formation of nanofibers inside mitochondria.

\section{APPLICATIONS IN CANCER THERAPY}

Although peptides and peptide-based vaccines and nanomaterials have been frequently reported for cancer therapy (Chiangjong et al., 2020; Malonis et al., 2020; Rong et al., 2020; Fan et al., 2021), the self-assembled peptidenanomaterials especially those targeting mitochondria as anticancer reagents are still in the primary stage. Currently, approaches of these nanomaterials for cancer therapy mainly include the delivery of anticancer drugs, destructions of mitochondria by mitochondria-cytotoxic peptides or peptideassemblies, and the combination with chemotherapy or photothermal therapy (PTT) (Supplementary Table S2). For instance, to deliver the chloramphenicol selectively to mitochondria, $\mathrm{He}$ et al. employed ENTK-instructed selfassembled peptide-nanoparticles as nanocarriers ( $\mathrm{He}$ et al., 2020b). Once arrived at mitochondria, the hydrophilic Flagtag on the peptide was cleaved by ENTK, resulting in the release of chloramphenicol to mitochondria. The chloramphenicol further interrupted the mitochondrial metabolism by inhibiting the synthesis of mitochondrial proteins, resulting in the release of cytochrome $c$ for apoptosis. This self-assembled nanoparticle showed selective cytotoxicity to tumor cells, with lower half-maximal inhibitory concentration $\left(\mathrm{IC}_{50}\right)$ values toward human hepatoma (HepG2) cells $(54 \mu \mathrm{M})$ and HeLa cells $(73 \mu \mathrm{M})$ than those for normal HS-5 cells $(143 \mu \mathrm{M})$ and murine hepatocyte (AML12) cells (142 $\mu \mathrm{M})$. The selectivity might be due to either the lack of ENTK enzymes in HS-5 cells or the less polarized mitochondria in AML12 cells. In addition, the peptideassemblies in mitochondria also show strong anticancer activities. For instance, Jeena et al. showed that the co-assembly of Mito-FF and its mirror formulation Mito-ff led to nanofibers with a diameter of $100 \mathrm{~nm}$, resulting in the enhanced antitumor efficacy in subcutaneous colorectal adenocarcinoma (HT-29)bearing mouse model via intraperitoneal injections (Jeena et al., 2019).

To realize the mitochondria-cytotoxic peptides for improved cancer therapy, Qiao et al. developed a type of PPCs containing KLAK peptides prepared by Michael-type addition (Qiao et al., 2016a). This synthetic method allowed the facile conjugations of targeted and therapeutic peptides together with PEG chains to a polymer backbone, achieving both the improved biological stability and enhanced anticancer efficacy toward the subcutaneous glioblastoma (U87)-bearing mouse model. However, this covalent approach suffers from the long reaction time (e.g., 2 days) and the competitive reactions from the thiol and amine groups. To construct a fast and simple method for systemic delivery of peptide pharmaceuticals, Wang et al. based on the concept of non-covalent supramolecular chemotherapy (Chen et al., 2017; Chen et al., 2018a; Wu et al., 2021), proposed a strategy of supramolecular peptide therapeutics (Wang H. et al., 2020). Owning to the strong host-guest interaction between the cucurbit[7]uril ( $\mathrm{CB}[7])$ and $\mathrm{N}$-terminal phenylalanine (N-Phe) residue in the peptide (binding constant $\sim 2 \times 10^{6} \mathrm{M}^{-1}$ ), the N-Phe-containing KLAK peptides were carried by the $\mathrm{CB}$ [7]-PEG copolymers in a simple (mixing in the aqueous solution) and fast (several minutes) manner with a high peptide encapsulation efficiency (>97\%) under the peptide concentration of $0.5 \mathrm{mM}$. This strategy achieved prolonged blood circulation $(25 \%$ remained at $1 \mathrm{~h}$ after intravenous injections compared with $13 \%$ for the peptide alone), enhanced tumor accumulation (2.8-fold enhancement), and increased anticancer efficacy (4-fold enhancement in the tumor inhibition rate) toward the subcutaneous colorectal tumor (HCT116)-bearing mouse model via intravenous injections, with minimal hematologic, hepatic, and nephric toxicities. In addition, to overcome the drug resistance of cancer cells, the same group further combined the oxaliplatin and KLAK peptide that disrupted ATP generations synergistically, in an acid-trigged on-demand drug release system (Figure 1E), achieving the improved anticancer activity toward oxaliplatin-resistant HCT116 cells, with $\mathrm{IC}_{50}$ decreased from $76.5 \mu \mathrm{M}$ (oxaliplatin) to $31.2 \mu \mathrm{M}$ (Wang H. et al., 2021). Besides chemotherapy, Zhang et al. utilized the photothermal effect irradiated by the near-infrared (NIR) light to promote the self-assembly of a purpurin-18containing peptide, resulting in a four times increase in the self-assembly rate and a 2 -fold enhancement in the tumor accumulation (Zhang et al., 2020). 


\section{CONCLUSION AND OUTLOOK}

The advances in nanotechnology and biotechnology have witnessed the great progress of the self-assembling peptides from simple scaffolds of hydrogels to smart nanomaterials for versatile biomedical applications, bridging the gap between simple synthetic molecules with sophisticated biological machinery in the body. Owning to the advantages including the excellent biocompatibility and the inclusivity for multiple biological and physicochemical activities, the self-assembling peptide achieves the self-assembled accuracy from levels of the tissue, through cells, to cellular organelles. However, several challenges still exist for the further development of mitochondria-targeted self-assembling peptides. The first is the precise self-assembly. Besides the membrane potential, enzyme, and ROS, other candidates such as the mitochondrial protein import machinery and nucleic acids (Zhao et al., 2021) are also promising targets. The second one is the characterization in situ. High-resolution, real-time, and in situ technologies are highly desirable to investigate the process and kinetics of the self-assembly in organelles. The third one is the rapid design and screening. The technology of machine learning may provide a high-throughput method to develop self-assembling peptides equipped with multiple bioactive and functional modules. Last but not least, biological safety should be highly concerned. Since the prolonged retention nature of the peptide nanofibers, careful

\section{REFERENCES}

Abbas, M., Zou, Q., Li, S., and Yan, X. (2017). Self-Assembled Peptide- and Protein-Based Nanomaterials for Antitumor Photodynamic and Photothermal Therapy. Adv. Mater. 29, 1605021. doi:10.1002/adma.201605021

Battogtokh, G., Choi, Y. S., Kang, D. S., Park, S. J., Shim, M. S., Huh, K. M., et al. (2018). Mitochondria-Targeting Drug Conjugates for Cytotoxic, AntiOxidizing and Sensing Purposes: Current Strategies and Future Perspectives. Acta Pharm. Sin. B 8, 862-880. doi:10.1016/j.apsb.2018.05.006

Birk, A. V., Liu, S., Soong, Y., Mills, W., Singh, P., Warren, J. D., et al. (2013). The Mitochondrial-Targeted Compound SS-31 Re-Energizes Ischemic Mitochondria by Interacting with Cardiolipin. J. Am. Soc. Nephrol. 24, 1250-1261. doi:10.1681/asn.2012121216

Bock, F. J., and Tait, S. W. G. (2020). Mitochondria as Multifaceted Regulators of Cell Death. Nat. Rev. Mol. Cell Biol. 21, 85-100. doi:10.1038/s41580-019-0173-8

Chandel, N. S. (2015). Evolution of Mitochondria as Signaling Organelles. Cell Metab. 22, 204-206. doi:10.1016/j.cmet.2015.05.013

Chandra Saha, P., Das, R. S., Chatterjee, T., Bhattacharyya, M., and Guha, S. (2020). Supramolecular $\beta$-Sheet Forming Peptide Conjugated with Near-Infrared Chromophore for Selective Targeting, Imaging, and Dysfunction of Mitochondria. Bioconjug. Chem. 31, 1301-1306. doi:10.1021/acs.bioconjchem.0c00153

Chen, H., Chen, Y., Wu, H., Xu, J.-F., Sun, Z., and Zhang, X. (2018a). Supramolecular Polymeric Chemotherapy Based on Cucurbit[7]uril-PEG Copolymer. Biomaterials 178, 697-705. doi:10.1016/j.biomaterials.2018.02.051

Chen, H., Gu, Z., An, H., Chen, C., Chen, J., Cui, R., et al. (2018b). Precise Nanomedicine for Intelligent Therapy of Cancer. Sci. China Chem. 61, 1503-1552. doi:10.1007/s11426-018-9397-5

Chen, Y., Huang, Z., Zhao, H., Xu, J.-F., Sun, Z., and Zhang, X. (2017). Supramolecular Chemotherapy: Cooperative Enhancement of Antitumor Activity by Combining Controlled Release of Oxaliplatin and Consuming of Spermine by Cucurbit[7]uril. ACS Appl. Mater. Inter. 9, 8602-8608. doi:10.1021/acsami.7b01157

Chen, Y., Yang, Y., Orr, A. A., Makam, P., Redko, B., Haimov, E., et al. (2021). SelfAssembled Peptide Nano-Superstructure towards Enzyme Mimicking studies in the degradation, metabolism, and long-term toxicology of the self-assembling peptides are important for their further clinical applications. Despite the challenges, we believe the self-assembled peptide-nanomaterials, especially the organelle-precise self-assembling peptides, will contribute to the new paradigms of biomedical technologies and products.

\section{AUTHOR CONTRIBUTIONS}

All authors listed have made a substantial, direct, and intellectual contribution to the work and approved it for publication.

\section{FUNDING}

This research was financially supported by the National Key R\&D Program of China (No. 2018YFE0205400) and the National Natural Science Foundation of China (Nos. 21805058 and 51890892).

\section{SUPPLEMENTARY MATERIAL}

The Supplementary Material for this article can be found online at: https://www.frontiersin.org/articles/10.3389/fbioe.2021.782234/ full\#supplementary-material
Hydrolysis. Angew. Chem. Int. Ed. 60, 17164-17170. doi:10.1002/ anie. 202105830

Cheng, D.-B., Yang, P.-P., Cong, Y., Liu, F.-H., Qiao, Z.-Y., and Wang, H. (2017). One-Pot Synthesis of pH-Responsive Hyperbranched Polymer-Peptide Conjugates with Enhanced Stability and Loading Efficiency for Combined Cancer Therapy. Polym. Chem. 8, 2462-2471. doi:10.1039/c7py00101k

Cheng, D.-B., Zhang, X.-H., Chen, Y., Chen, H., Qiao, Z.-Y., and Wang, H. (2020). Ultrasound-Activated Cascade Effect for Synergistic Orthotopic Pancreatic Cancer Therapy. iScience 23, 101144. doi:10.1016/j.isci.2020.101144

Cheng, D.-B., Zhang, X.-H., Gao, Y.-J., Ji, L., Hou, D., Wang, Z., et al. (2019). Endogenous Reactive Oxygen Species-Triggered Morphology Transformation for Enhanced Cooperative Interaction with Mitochondria. J. Am. Chem. Soc. 141, 7235-7239. doi:10.1021/jacs.8b07727

Chiangjong, W., Chutipongtanate, S., and Hongeng, S. (2020). Anticancer Peptide: Physicochemical Property, Functional Aspect and Trend in Clinical Application (Review). Int. J. Oncol. 57, 678-696. doi:10.3892/ijo.2020.5099

Chuah, J.-A., Matsugami, A., Hayashi, F., and Numata, K. (2016). Self-Assembled Peptide-Based System for Mitochondrial-Targeted Gene Delivery: Functional and Structural Insights. Biomacromolecules 17, 3547-3557. doi:10.1021/ acs.biomac.6b01056

Cong, Y., Ji, L., Gao, Y. J., Liu, F. H., Cheng, D. B., Hu, Z., et al. (2019). Microenvironment-Induced In Situ Self-Assembly of Polymer-Peptide Conjugates that Attack Solid Tumors Deeply. Angew. Chem. Int. Ed. 58, 4632-4637. doi:10.1002/anie.201900135

Cui, H., Webber, M. J., and Stupp, S. I. (2010). Self-Assembly of Peptide Amphiphiles: From Molecules to Nanostructures to Biomaterials. Biopolymers 94, 1-18. doi:10.1002/bip.21328

Deng, Y., Zhan, W., and Liang, G. (2021). Intracellular Self-Assembly of Peptide Conjugates for Tumor Imaging and Therapy. Adv. Healthc. Mater. 10, e2001211. doi:10.1002/adhm.202001211

Devine, M. J., and Kittler, J. T. (2018). Mitochondria at the Neuronal Presynapse in Health and Disease. Nat. Rev. Neurosci. 19, 63-80. doi:10.1038/nrn.2017.170

Diebold, L. P., Gil, H. J., Gao, P., Martinez, C. A., Weinberg, S. E., and Chandel, N. S. (2019). Mitochondrial Complex III Is Necessary for Endothelial Cell 
Proliferation during Angiogenesis. Nat. Metab. 1, 158-171. doi:10.1038/ s42255-018-0011-x

Ellerby, H. M., Arap, W., Ellerby, L. M., Kain, R., Andrusiak, R., Rio, G. D., et al. (1999). Anti-Cancer Activity of Targeted pro-Apoptotic Peptides. Nat. Med. 5, 1032-1038. doi:10.1038/12469

Fan, Y., Liu, S., Yi, Y., Rong, H., and Zhang, J. (2021). Catalytic Nanomaterials toward Atomic Levels for Biomedical Applications: From Metal Clusters to Single-Atom Catalysts. ACS Nano 15, 2005-2037. doi:10.1021/ acsnano.0c06962

Frederix, P. W. J. M., Scott, G. G., Abul-Haija, Y. M., Kalafatovic, D., Pappas, C. G., Javid, N., et al. (2015). Exploring the Sequence Space for (Tri-)peptide SelfAssembly to Design and Discover New Hydrogels. Nat. Chem. 7, 30-37. doi: $10.1038 /$ nchem. 2122

Frey, T. G., and Mannella, C. A. (2000). The Internal Structure of Mitochondria. Trends Biochem. Sci. 25, 319-324. doi:10.1016/s0968-0004(00)01609-1

Fulda, S., Galluzzi, L., and Kroemer, G. (2010). Targeting Mitochondria for Cancer Therapy. Nat. Rev. Drug Discov. 9, 447-464. doi:10.1038/nrd3137

Gao, Y., Tong, H., Li, J., Li, J., Huang, D., Shi, J., et al. (2021). MitochondriaTargeted Nanomedicine for Enhanced Efficacy of Cancer Therapy. Front. Bioeng. Biotechnol. 9, 720508. doi:10.3389/fbioe.2021.720508

Gelain, F., Luo, Z., and Zhang, S. (2020). Self-Assembling Peptide EAK16 and RADA16 Nanofiber Scaffold Hydrogel. Chem. Rev. 120, 13434-13460. doi:10.1021/acs.chemrev.0c00690

Gray, M. W., Burger, G., and Lang, B. F. (1999). Mitochondrial Evolution. Science 283, 1476-1481. doi:10.1126/science.283.5407.1476

Guo, X., Yang, N., Ji, W., Zhang, H., Dong, X., Zhou, Z., et al. (2021). Mito-Bomb: Targeting Mitochondria for Cancer Therapy. Adv. Mater. 33, 2007778. doi:10.1002/adma.202007778

Guyon, L., Lepeltier, E., and Passirani, C. (2018). Self-Assembly of Peptide-Based Nanostructures: Synthesis and Biological Activity. Nano Res. 11, 2315-2335. doi:10.1007/s12274-017-1892-9

He, H., Guo, J., Lin, X., and Xu, B. (2020a). Enzyme-Instructed Assemblies Enable Mitochondria Localization of Histone H2B in Cancer Cells. Angew. Chem. Int. Ed. 59, 9330-9334. doi:10.1002/anie.202000983

He, H., Lin, X., Guo, J., Wang, J., and Xu, B. (2020b). Perimitochondrial Enzymatic Self-Assembly for Selective Targeting the Mitochondria of Cancer Cells. ACS Nano 14, 6947-6955. doi:10.1021/acsnano.0c01388

He, H., Tan, W., Guo, J., Yi, M., Shy, A. N., and Xu, B. (2020c). Enzymatic Noncovalent Synthesis. Chem. Rev. 120, 9994-10078. doi:10.1021/ acs.chemrev.0c00306

He, H., Wang, J., Wang, H., Zhou, N., Yang, D., Green, D. R., et al. (2018). Enzymatic Cleavage of Branched Peptides for Targeting Mitochondria. J. Am. Chem. Soc. 140, 1215-1218. doi:10.1021/jacs.7b11582

He, P.-P., Li, X.-D., Fan, J.-Q., Fan, Y., Yang, P.-P., Li, B.-N., et al. (2020d). Live Cells Process Exogenous Peptide as Fibronectin Fibrillogenesis In Vivo. CCS Chem. 2, 539-554. doi:10.31635/ccschem.020.201900117

Hendricks, M. P., Sato, K., Palmer, L. C., and Stupp, S. I. (2017). Supramolecular Assembly of Peptide Amphiphiles. Acc. Chem. Res. 50, 2440-2448. doi:10.1021/ acs.accounts.7b00297

Hong, T. H., Jeena, M. T., Kim, O.-H., Kim, K.-H., Choi, H. J., Lee, K. H., et al. (2021). Application of Self-Assembly Peptides Targeting the Mitochondria as a Novel Treatment for Sorafenib-Resistant Hepatocellular Carcinoma Cells. Sci. Rep. 11, 874. doi:10.1038/s41598-020-79536-z

Horton, K. L., Stewart, K. M., Fonseca, S. B., Guo, Q., and Kelley, S. O. (2008). Mitochondria-Penetrating Peptides. Chem. Biol. 15, 375-382. doi:10.1016/ j.chembiol.2008.03.015

Hosoyama, K., Lazurko, C., Muñoz, M., Mctiernan, C. D., and Alarcon, E. I. (2019). Peptide-Based Functional Biomaterials for Soft-Tissue Repair. Front. Bioeng. Biotechnol. 7, 205. doi:10.3389/fbioe.2019.00205

Hu, K., Jiang, Y., Xiong, W., Li, H., Zhang, P. Y., Yin, F., et al. (2018). Tuning Peptide Self-Assembly by an In-Tether Chiral Center. Sci. Adv. 4, eaar5907. doi:10.1126/sciadv.aar5907

Hu, K., Xiong, W., Sun, C., Wang, C., Li, J., Yin, F., et al. (2020). Self-Assembly of Constrained Cyclic Peptides Controlled by Ring Size. CCS Chem. 2, 42-51. doi:10.31635/ccschem.020.201900047

Jean, S. R., Ahmed, M., Lei, E. K., Wisnovsky, S. P., and Kelley, S. O. (2016). PeptideMediated Delivery of Chemical Probes and Therapeutics to Mitochondria. Acc. Chem. Res. 49, 1893-1902. doi:10.1021/acs.accounts.6b00277
Jeena, M. T., Kim, S., Jin, S., and Ryu, J. H. (2020a). Recent Progress in Mitochondria-Targeted Drug and Drug-free Agents for Cancer Therapy. Cancers (Basel) 12, 4. doi:10.3390/cancers12010004

Jeena, M. T., Jeong, K., Go, E. M., Cho, Y., Lee, S., Jin, S., et al. (2019). Heterochiral Assembly of Amphiphilic Peptides inside the Mitochondria for Supramolecular Cancer Therapeutics. ACS Nano 13, 11022-11033. doi:10.1021/ acsnano.9b02522

Jeena, M. T., Lee, S., Barui, A. K., Jin, S., Cho, Y., Hwang, S.-W., et al. (2020b). IntraMitochondria Self-Assembly to Overcome the Intracellular Enzymatic Degradation of L-Peptides. Chem. Commun. 56, 6265-6268. doi:10.1039/ d0cc02029j

Jeena, M. T., Palanikumar, L., Go, E. M., Kim, I., Kang, M. G., Lee, S., et al. (2017). Mitochondria Localization Induced Self-Assembly of Peptide Amphiphiles for Cellular Dysfunction. Nat. Commun. 8, 26. doi:10.1038/s41467-017-00047-z

Ji, T., Li, Y., Deng, X., Rwei, A. Y., Offen, A., Hall, S., et al. (2021). Delivery of Local Anaesthetics by a Self-Assembled Supramolecular System Mimicking Their Interactions with a Sodium Channel. Nat. Biomed. Eng. 5, 1099-1109. doi:10.1038/s41551-021-00793-y

Jiang, T., Liu, C., Xu, X., He, B., and Mo, R. (2021). Formation Mechanism and Biomedical Applications of Protease-Manipulated Peptide Assemblies. Front. Bioeng. Biotechnol. 9, 598050. doi:10.3389/fbioe.2021.598050

Jiao, H., Jiang, D., Hu, X., Du, W., Ji, L., Yang, Y., et al. (2021). Mitocytosis, a Migrasome-Mediated Mitochondrial Quality-Control Process. Cell 184, 2896-2910. doi:10.1016/j.cell.2021.04.027

Jumper, J., Evans, R., Pritzel, A., Green, T., Figurnov, M., Ronneberger, O., et al. (2021). Highly Accurate Protein Structure Prediction with Alphafold. Nature 596, 583-589. doi:10.1038/s41586-021-03819-2

Kang, H. C. (2018). Mitochondria-Targeting Theranostics. Biomater. Res. 22, 34 doi:10.1186/s40824-018-0145-7

Kelso, G. F., Porteous, C. M., Coulter, C. V., Hughes, G., Porteous, W. K., Ledgerwood, E. C., et al. (2001). Selective Targeting of a Redox-Active Ubiquinone to Mitochondria within Cells. J. Biol. Chem. 276, 4588-4596. doi:10.1074/jbc.m009093200

Kleele, T., Rey, T., Winter, J., Zaganelli, S., Mahecic, D., Perreten Lambert, H., et al. (2021). Distinct Fission Signatures Predict Mitochondrial Degradation or Biogenesis. Nature 593, 435-439. doi:10.1038/s41586-021-03510-6

Kumar, K., Moitra, P., Bashir, M., Kondaiah, P., and Bhattacharya, S. (2020). Natural Tripeptide Capped pH-Sensitive Gold Nanoparticles for Efficacious Doxorubicin Delivery Both In Vitro and In Vivo. Nanoscale 12, 1067-1074. doi:10.1039/c9nr08475d

Kwek, G., Do, T. C., Lu, X., Lin, J., and Xing, B. (2021). Scratching the Surface of Unventured Possibilities with In Situ Self-Assembly: Protease-Activated Developments for Imaging and Therapy. ACS Appl. Bio Mater. 4, 2192-2216. doi:10.1021/acsabm.0c01340

Lam, K. S., Salmon, S. E., Hersh, E. M., Hruby, V. J., Kazmierski, W. M., and Knapp, R. J. (1991). A New Type of Synthetic Peptide Library for Identifying LigandBinding Activity. Nature 354, 82-84. doi:10.1038/354082a0

Lee, J.-H., Heo, K., Schulz-Schönhagen, K., Lee, J. H., Desai, M. S., Jin, H.-E., et al. (2018). Diphenylalanine Peptide Nanotube Energy Harvesters. ACS Nano 12, 8138-8144. doi:10.1021/acsnano.8b03118

Levin, A., Hakala, T. A., Schnaider, L., Bernardes, G. J. L., Gazit, E., and Knowles, T. P. J. (2020). Biomimetic Peptide Self-Assembly for Functional Materials. Nat. Rev. Chem. 4, 615-634. doi:10.1038/s41570-020-0215-y

Li, C., Iscen, A., Sai, H., Sato, K., Sather, N. A., Chin, S. M., et al. (2020). Supramolecular-Covalent Hybrid Polymers for Light-Activated Mechanical Actuation. Nat. Mater. 19, 900-909. doi:10.1038/s41563-020-0707-7

Li, F., Han, J., Cao, T., Lam, W., Fan, B., Tang, W., et al. (2019a). Design of Self-Assembly Dipeptide Hydrogels and Machine Learning via Their Chemical Features. Proc. Natl. Acad. Sci. USA 116, 11259-11264. doi:10.1073/pnas.1903376116

Li, L. L., Qiao, Z. Y., Wang, L., and Wang, H. (2019b). Programmable Construction of Peptide-Based Materials in Living Subjects: From Modular Design and Morphological Control to Theranostics. Adv. Mater. 31, e1804971. doi:10.1002/adma.201804971

Li, Q., and Huang, Y. (2020). Mitochondrial Targeted Strategies and Their Application for Cancer and Other Diseases Treatment. J. Pharm. Investig. 50, 271-293. doi:10.1007/s40005-020-00481-0

Liberman, E. A., Topaly, V. P., Tsofina, L. M., Jasaitis, A. A., and Skulachev, V. P. (1969). Mechanism of Coupling of Oxidative Phosphorylation and the 
Membrane Potential of Mitochondria. Nature 222, 1076-1078. doi:10.1038/ 2221076a0

Liew, S. S., Qin, X., Zhou, J., Li, L., Huang, W., and Yao, S. Q. (2021). Smart Design of Nanomaterials for Mitochondria-Targeted Nanotherapeutics. Angew. Chem. Int. Ed. 60, 2232-2256. doi:10.1002/anie.201915826

Liu, D., Angelova, A., Liu, J., Garamus, V. M., Angelov, B., Zhang, X., et al. (2019). Self-Assembly of Mitochondria-Specific Peptide Amphiphiles Amplifying Lung Cancer Cell Death through Targeting the VDAC1-Hexokinase-II Complex. J. Mater. Chem. B 7, 4706-4716. doi:10.1039/c9tb00629j

Liu, F.-H., Cong, Y., Qi, G.-B., Ji, L., Qiao, Z.-Y., and Wang, H. (2018a). NearInfrared Laser-Driven In Situ Self-Assembly as a General Strategy for Deep Tumor Therapy. Nano Lett. 18, 6577-6584. doi:10.1021/acs.nanolett.8b03174

Liu, F.-H., Hou, C.-Y., Zhang, D., Zhao, W.-J., Cong, Y., Duan, Z.-Y., et al. (2018b). Enzyme-Sensitive Cytotoxic Peptide-Dendrimer Conjugates Enhance Cell Apoptosis and Deep Tumor Penetration. Biomater. Sci. 6, 604-613. doi:10.1039/c7bm01182b

Liu, N., Zhu, L., Li, Z., Liu, W., Sun, M., and Zhou, Z. (2021a). In Situ SelfAssembled Peptide Nanofibers for Cancer Theranostics. Biomater. Sci. 9, 5427-5436. doi:10.1039/d1bm00782c

Liu, Q., Wan, K., Shang, Y., Wang, Z.-G., Zhang, Y., Dai, L., et al. (2021b). Cofactor-Free Oxidase-Mimetic Nanomaterials from Self-Assembled Histidine-Rich Peptides. Nat. Mater. 20, 395-402. doi:10.1038/s41563-02000856-6

Lopez-Silva, T. L., and Schneider, J. P. (2021). From Structure to Application: Progress and Opportunities in Peptide Materials Development. Curr. Opin. Chem. Biol. 64, 131-144. doi:10.1016/j.cbpa.2021.06.006

Löwik, D. W. P. M., and Van Hest, J. C. M. (2004). Peptide Based Amphiphiles. Chem. Soc. Rev. 33, 234-245. doi:10.1039/b212638a

Malonis, R. J., Lai, J. R., and Vergnolle, O. (2020). Peptide-Based Vaccines: Current Progress and Future Challenges. Chem. Rev. 120, 3210-3229. doi:10.1021/ acs.chemrev.9b00472

Mamuti, M., Zheng, R., An, H.-W., and Wang, H. (2021). In Vivo Self-Assembled Nanomedicine. Nano Today 36, 101036. doi:10.1016/j.nantod.2020.101036

Manzari, M. T., Shamay, Y., Kiguchi, H., Rosen, N., Scaltriti, M., and Heller, D. A. (2021). Targeted Drug Delivery Strategies for Precision Medicines. Nat. Rev. Mater. 6, 351-370. doi:10.1038/s41578-020-00269-6

Merrifield, R. B. (1963). Solid Phase Peptide Synthesis. I. The Synthesis of a Tetrapeptide. J. Am. Chem. Soc. 85, 2149-2154. doi:10.1021/ja00897a025

Mi, P., Cabral, H., and Kataoka, K. (2020). Ligand-Installed Nanocarriers toward Precision Therapy. Adv. Mater. 32, e1902604. doi:10.1002/adma.201902604

Moitra, P., Kumar, K., Kondaiah, P., and Bhattacharya, S. (2014). Efficacious Anticancer Drug Delivery Mediated by a pH-Sensitive Self-Assembly of a Conserved Tripeptide Derived from Tyrosine Kinase NGF Receptor. Angew. Chem. Int. Ed. 53, 1113-1117. doi:10.1002/anie.201307247

Moitra, P., Subramanian, Y., and Bhattacharya, S. (2017). Concentration Dependent Self-Assembly of TrK-NGF Receptor Derived Tripeptide: New Insights from Experiment and Computer Simulations. J. Phys. Chem. B 121, 815-824. doi:10.1021/acs.jpcb.6b10511

Murphy, M. P., and Hartley, R. C. (2018). Mitochondria as a Therapeutic Target for Common Pathologies. Nat. Rev. Drug Discov. 17, 865-886. doi:10.1038/ nrd.2018.174

Murphy, M. P., and Smith, R. A. J. (2007). Targeting Antioxidants to Mitochondria by Conjugation to Lipophilic Cations. Annu. Rev. Pharmacol. Toxicol. 47, 629-656. doi:10.1146/annurev.pharmtox.47.120505.105110

Muttenthaler, M., King, G. F., Adams, D. J., and Alewood, P. F. (2021). Trends in Peptide Drug Discovery. Nat. Rev. Drug Discov. 20, 309-325. doi:10.1038/ s41573-020-00135-8

Neupert, W., and Herrmann, J. M. (2007). Translocation of Proteins into Mitochondria. Annu. Rev. Biochem. 76, 723-749. doi:10.1146/ annurev.biochem.76.052705.163409

Nguyen, T. P., Easley, A. D., Kang, N., Khan, S., Lim, S.-M., Rezenom, Y. H., et al. (2021). Polypeptide Organic Radical Batteries. Nature 593, 61-66. doi:10.1038/ s41586-021-03399-1

Nunnari, J., and Suomalainen, A. (2012). Mitochondria: In Sickness and in Health. Cell 148, 1145-1159. doi:10.1016/j.cell.2012.02.035

Qi, G. B., Gao, Y. J., Wang, L., and Wang, H. (2018). Self-Assembled Peptide-Based Nanomaterials for Biomedical Imaging and Therapy. Adv. Mater. 30, e1703444. doi:10.1002/adma.201703444
Qiao, Z.-Y., Lai, W.-J., Lin, Y.-X., Li, D., Nan, X.-H., Wang, Y., et al. (2017a). Polymer-KLAK Peptide Conjugates Induce Cancer Cell Death through Synergistic Effects of Mitochondria Damage and Autophagy Blockage. Bioconjug. Chem. 28, 1709-1721. doi:10.1021/acs.bioconjchem.7b00176

Qiao, Z.-Y., Lin, Y.-X., Lai, W.-J., Hou, C.-Y., Wang, Y., Qiao, S.-L., et al. (2016a). A General Strategy for Facile Synthesis and In Situ Screening of Self-Assembled Polymer-Peptide Nanomaterials. Adv. Mater. 28, 1859-1867. doi:10.1002/ adma.201504564

Qiao, Z.-Y., Zhao, W.-J., Cong, Y., Zhang, D., Hu, Z., Duan, Z.-Y., et al. (2016b). Self-Assembled ROS-Sensitive Polymer-Peptide Therapeutics Incorporating Built-In Reporters for Evaluation of Treatment Efficacy. Biomacromolecules 17, 1643-1652. doi:10.1021/acs.biomac.6b00041

Qiao, Z.-Y., Zhao, W.-J., Gao, Y.-J., Cong, Y., Zhao, L., Hu, Z., et al. (2017b). Reconfigurable Peptide Nanotherapeutics at Tumor Microenvironmental $\mathrm{pH}$. ACS Appl. Mater. Inter. 9, 30426-30436. doi:10.1021/acsami.7b09033

Reches, M., and Gazit, E. (2003). Casting Metal Nanowires within Discrete SelfAssembled Peptide Nanotubes. Science 300, 625-627. doi:10.1126/ science. 1082387

Roger, A. J., Muñoz-Gómez, S. A., and Kamikawa, R. (2017). The Origin and Diversification of Mitochondria. Curr. Biol. 27, R1177-R1192. doi:10.1016/ j.cub.2017.09.015

Rong, L., Lei, Q., and Zhang, X. Z. (2020). Recent Advances on Peptide-Based Theranostic Nanomaterials. View 1, 20200050. doi:10.1002/viw.20200050

Rufo, C. M., Moroz, Y. S., Moroz, O. V., Stöhr, J., Smith, T. A., Hu, X., et al. (2014). Short Peptides Self-Assemble to Produce Catalytic Amyloids. Nat. Chem. 6, 303-309. doi:10.1038/nchem.1894

Saha, P. C., Bera, T., Chatterjee, T., Samanta, J., Sengupta, A., Bhattacharyya, M., et al. (2021). Supramolecular Dipeptide-Based Near-Infrared Fluorescent Nanotubes for Cellular Mitochondria Targeted Imaging and Early Apoptosis. Bioconjug. Chem. 32, 833-841. doi:10.1021/ acs.bioconjchem.1c00106

Seo, B., Yoon, S., and Do, J. (2018). Mitochondrial Dynamics in Stem Cells and Differentiation. Int. J. Mol. Sci. 19, 3893. doi:10.3390/ijms19123893

Siasos, G., Tsigkou, V., Kosmopoulos, M., Theodosiadis, D., Simantiris, S., Tagkou, N. M., et al. (2018). Mitochondria and Cardiovascular Diseases-From Pathophysiology to Treatment. Ann. Transl. Med. 6, 256. doi:10.21037/ atm.2018.06.21

Skulachev, V. P. (2007). A Biochemical Approach to the Problem of Aging: "Megaproject" on Membrane-Penetrating Ions. The First Results and Prospects. Biochem. Mosc. 72, 1385-1396. doi:10.1134/ s0006297907120139

Smith, G. P. (1985). Filamentous Fusion Phage: Novel Expression Vectors that Display Cloned Antigens on the Virion Surface. Science 228, 1315-1317. doi:10.1126/science.4001944

Smith, R. A. J., Hartley, R. C., Cochemé, H. M., and Murphy, M. P. (2012). Mitochondrial Pharmacology. Trends Pharmacol. Sci. 33, 341-352. doi:10.1016/ j.tips.2012.03.010

Spinelli, J. B., and Haigis, M. C. (2018). The Multifaceted Contributions of Mitochondria to Cellular Metabolism. Nat. Cell Biol. 20, 745-754. doi:10.1038/s41556-018-0124-1

Standley, S. M., Toft, D. J., Cheng, H., Soukasene, S., Chen, J., Raja, S. M., et al. (2010). Induction of Cancer Cell Death by Self-Assembling Nanostructures Incorporating a Cytotoxic Peptide. Cancer Res. 70, 3020-3026. doi:10.1158/ 0008-5472.can-09-3267

Sun, Q., Zhou, Z., Qiu, N., and Shen, Y. (2017). Rational Design of Cancer Nanomedicine: Nanoproperty Integration and Synchronization. Adv. Mater. 29, 1606628. doi:10.1002/adma.201606628

Tao, K., Makam, P., Aizen, R., and Gazit, E. (2017). Self-Assembling Peptide Semiconductors. Science 358, eaam9756. doi:10.1126/science.aam9756

Vasan, K., Werner, M., and Chandel, N. S. (2020). Mitochondrial Metabolism as a Target for Cancer Therapy. Cell Metab. 32, 341-352. doi:10.1016/ j.cmet.2020.06.019

Wang, H., Feng, Z., Wang, Y., Zhou, R., Yang, Z., and Xu, B. (2016). Integrating Enzymatic Self-Assembly and Mitochondria Targeting for Selectively Killing Cancer Cells without Acquired Drug Resistance. J. Am. Chem. Soc. 138, 16046-16055. doi:10.1021/jacs.6b09783

Wang, H., Wu, H., Yi, Y., Xue, K.-F., Xu, J.-F., Wang, H., et al. (2021a). SelfMotivated Supramolecular Combination Chemotherapy for Overcoming Drug 
Resistance Based on Acid-Activated Competition of Host-Guest Interactions. CCS Chem. 3, 1413-1425. doi:10.31635/ccschem.021.202100964

Wang, H., Yan, Y.-Q., Yi, Y., Wei, Z.-Y., Chen, H., Xu, J.-F., et al. (2020a). Supramolecular Peptide Therapeutics: Host-Guest Interaction-Assisted Systemic Delivery of Anticancer Peptides. CCS Chem. 2, 739-748. doi: $10.31635 /$ ccschem. 020.202000283

Wang, M., Zhang, Q., Jian, H., Liu, S., Li, J., Wang, A., et al. (2020b). Role of Thermolysin in Catalytic-Controlled Self-Assembly of Fmoc-Dipeptides. CCS Chem. 2, 317-328. doi:10.31635/ccschem.020.201900116

Wang, Y., Weng, J., Wen, X., Hu, Y., and Ye, D. (2021b). Recent Advances in Stimuli-Responsive In Situ Self-Assembly of Small Molecule Probes for In Vivo Imaging of Enzymatic Activity. Biomater. Sci. 9, 406-421. doi:10.1039/ d0bm00895h

Ward, P. S., and Thompson, C. B. (2012). Metabolic Reprogramming: A Cancer Hallmark Even Warburg Did Not Anticipate. Cancer Cell 21, 297-308. doi:10.1016/j.ccr.2012.02.014

Wasilewski, M., Chojnacka, K., and Chacinska, A. (2017). Protein Trafficking at the Crossroads to Mitochondria. Biochim. Biophys. Acta (Bba) - Mol. Cell Res. 1864, 125-137. doi:10.1016/j.bbamcr.2016.10.019

Wei, G., Su, Z., Reynolds, N. P., Arosio, P., Hamley, I. W., Gazit, E., et al. (2017). Self-Assembled Peptide and Protein Amyloids: From Structure to Tailored Function in Nanotechnology. Chem. Soc. Rev. 46, 4661-4708. doi:10.1039/ c6cs00542j

Weinberg, S. E., and Chandel, N. S. (2015). Targeting Mitochondria Metabolism for Cancer Therapy. Nat. Chem. Biol. 11, 9-15. doi:10.1038/nchembio.1712

Wu, H., Wang, H., Qi, F., Xia, T., Xia, Y., Xu, J.-F., et al. (2021). An Activatable HostGuest Conjugate as a Nanocarrier for Effective Drug Release through Self-Inclusion. ACS Appl. Mater. Inter. 13, 33962-33968. doi:10.1021/acsami.1c09823

Yang, J., An, H.-W., and Wang, H. (2020a). Self-Assembled Peptide Drug Delivery Systems. ACS Appl. Bio Mater. 4, 24-46. doi:10.1021/acsabm.0c00707

Yang, L., Peltier, R., Zhang, M., Song, D., Huang, H., Chen, G., et al. (2020b). Desuccinylation-Triggered Peptide Self-Assembly: Live Cell Imaging of SIRT5 Activity and Mitochondrial Activity Modulation. J. Am. Chem. Soc. 142, 18150-18159. doi:10.1021/jacs.0c08463

Yang, P.-P., Li, Y.-J., Cao, Y., Zhang, L., Wang, J.-Q., Lai, Z., et al. (2021). Rapid Discovery of Self-Assembling Peptides with One-Bead OneCompound Peptide Library. Nat. Commun. 12, 4494. doi:10.1038/ s41467-021-24597-5

Yi, Y., Kim, H. J., Zheng, M., Mi, P., Naito, M., Kim, B. S., et al. (2019). GlucoseLinked Sub-50-nm Unimer Polyion Complex-Assembled Gold Nanoparticles for Targeted siRNA Delivery to Glucose Transporter 1-Overexpressing Breast Cancer Stem-Like Cells. J. Control. Release 295, 268-277. doi:10.1016/ j.jconrel.2019.01.006

Zhang, D., Qi, G.-B., Zhao, Y.-X., Qiao, S.-L., Yang, C., and Wang, H. (2015). In Situ Formation of Nanofibers from Purpurin18-Peptide Conjugates and the Assembly Induced Retention Effect in Tumor Sites. Adv. Mater. 27, 6125-6130. doi:10.1002/adma.201502598

Zhang, S. (2003). Fabrication of Novel Biomaterials through Molecular SelfAssembly. Nat. Biotechnol. 21, 1171-1178. doi:10.1038/nbt874
Zhang, S. (2020). Self-Assembling Peptides: From a Discovery in a Yeast Protein to Diverse Uses and Beyond. Protein Sci. 29, 2281-2303. doi:10.1002/pro.3951

Zhang, X.-H., Cheng, D.-B., Ji, L., An, H.-W., Wang, D., Yang, Z.-X., et al. (2020). Photothermal-Promoted Morphology Transformation In Vivo Monitored by Photoacoustic Imaging. Nano Lett. 20, 1286-1295. doi:10.1021/ acs.nanolett.9b04752

Zhang, Z., Chai, Y., Zhao, H., Yang, S., Liu, W., Yang, Z., et al. (2021). Crosstalk between PC12 Cells and Endothelial Cells in an Artificial Neurovascular Niche Constructed by a Dual-Functionalized Self-Assembling Peptide Nanofiber Hydrogel. Nano Res. doi:10.1007/s12274-021-3684-5

Zhao, J., Li, Z., Shao, Y., Hu, W., and Li, L. (2021). Spatially Selective Imaging of Mitochondrial microRNAs via Optically Programmable Strand Displacement Reactions. Angew. Chem. Int. Ed. 60, 17937-17941. doi:10.1002/ anie. 202105696

Zhao, K., Zhao, G.-M., Wu, D., Soong, Y., Birk, A. V., Schiller, P. W., et al. (2004). Cell-Permeable Peptide Antioxidants Targeted to Inner Mitochondrial Membrane Inhibit Mitochondrial Swelling, Oxidative Cell Death, and Reperfusion Injury. J. Biol. Chem. 279, 34682-34690. doi:10.1074/ jbc.m402999200

Zhao, L., Li, S., Liu, Y., Xing, R., and Yan, X. (2019). Kinetically Controlled SelfAssembly of Phthalocyanine-Peptide Conjugate Nanofibrils Enabling Superlarge Redshifted Absorption. CCS Chem. 1, 173-180. doi:10.31635/ ccschem.019.20180017

Zheng, Y., Mao, K., Chen, S., and Zhu, H. (2021). Chirality Effects in Peptide Assembly Structures. Front. Bioeng. Biotechnol. 9, 703004. doi:10.3389/ fbioe. 2021.703004

Zhou, J., and Xu, B. (2015). Enzyme-Instructed Self-Assembly: A Multistep Process for Potential Cancer Therapy. Bioconjug. Chem. 26, 987-999. doi:10.1021/ acs.bioconjchem.5b00196

Zinovkin, R. A., and Zamyatnin, A. A. (2019). Mitochondria-Targeted Drugs. Curr. Mol. Pharmacol. 12, 202-214. doi:10.2174/1874467212666181127151059

Conflict of Interest: The authors declare that the research was conducted in the absence of any commercial or financial relationships that could be construed as a potential conflict of interest.

Publisher's Note: All claims expressed in this article are solely those of the authors and do not necessarily represent those of their affiliated organizations, or those of the publisher, the editors and the reviewers. Any product that may be evaluated in this article, or claim that may be made by its manufacturer, is not guaranteed or endorsed by the publisher.

Copyright $\odot 2021$ Luo, Gao, Duan, Yi and Wang. This is an open-access article distributed under the terms of the Creative Commons Attribution License (CC BY). The use, distribution or reproduction in other forums is permitted, provided the original author(s) and the copyright owner(s) are credited and that the original publication in this journal is cited, in accordance with accepted academic practice. No use, distribution or reproduction is permitted which does not comply with these terms. 